Rev Chil Salud Pública 2012;

Vol 16 (3): 207

Editorial

\title{
Imaginación sociológica para la salud pública chilena
}

\author{
SOCIOLOGICAL IMAGINATION FOR CHILEAN PUBLIC HEALTH
}

El trabajo editorial en salud pública contiene asperezas. Muchos de los artículos recibidos dejan la sensación de algo que pudiera haber sido diferente. Que las preguntas pudieran haber provocado una investigación más aventurada, un uso heterogéneo de herramientas procedentes de otros campos, que se arriesgaran más créditos en métodos alternativos, que la expresión escrita de las conclusiones transmitiera las inquietudes de los autores, la pasión de sus estudios.

Buena parte de los artículos que nos llegan parecen ser indiferentes al objeto de estudio. Los métodos y la metodología se mueven con independencia de aquello a lo que se interroga. Las técnicas intelectuales de trabajo para producir un resultado aparecen desvinculadas de aquello que se estudia.

Releyendo a Wright Mills, somos sorprendidos por la vigencia que tienen para la salud pública, sus comentarios de 1959 respecto a la sociología académica y a la necesaria imaginación sociológica.

En la condición epidemiológica actual parecemos dominados también por las tres fuerzas de la gran teoría, el empirismo abstracto y el ethos burocrático. Una teoría a salvo de de errores, tan abstracta que nada la pone en tela de juicio, una gran constructora de categorías como funcional/disfuncional, adaptado/desadaptado, normal/anormal. Un fetichismo de los conceptos como si estuvieran revestidos de una inocente positividad: dureza de los datos que a la hora de las pruebas son bastante blandos. Y finalmente, un sistema de organización de la investigación y de su evaluación que bloquean la innovación, las hipótesis inciertas, por el método clásico, la hipótesis ya confirmada, el resultado garantizado.

Contra esos modelos vigentes, se vuelve imprescindible que los salubristas lean más literatura e historia, que se animen con la sociología contemporánea, que pierdan el miedo a las etnografías y a los trucos del oficio. Que den a los números los que en justa medida les corresponde, pero que tributen a su esfuerzo, al oficio y a la artesanía en la investigación también lo que en proporcional magnitud les corresponde. Que no teman a la intersección de sus anhelos, de su vida y temores en medio de sus inquietudes investigativas.

La salud pública, a su manera, es una sociología del mundo contemporáneo, visto a la luz de la enfermedad y la salud. Las palabras del apéndice de La imaginación sociológica aún viven tras más de 50 años de haber sido escritas:

"Sabed que el sentido humano de las cuestiones públicas debe revelarse relacionándolas con las inquietudes personales y con los problemas de la vida individual. Sabed que los problemas de la ciencia social, cuando se formulan adecuadamente, deben comprender inquietudes personales y cuestiones públicas, biografía e historia, y el ámbito de sus intrincadas relaciones. Dentro de ese ámbito ocurren la ida del individuo y la actividad de las sociedades; y dentro de ese ámbito tiene la imaginación sociológica sus oportunidades para diferenciar la calidad de la vida humana en nuestro tiempo." 